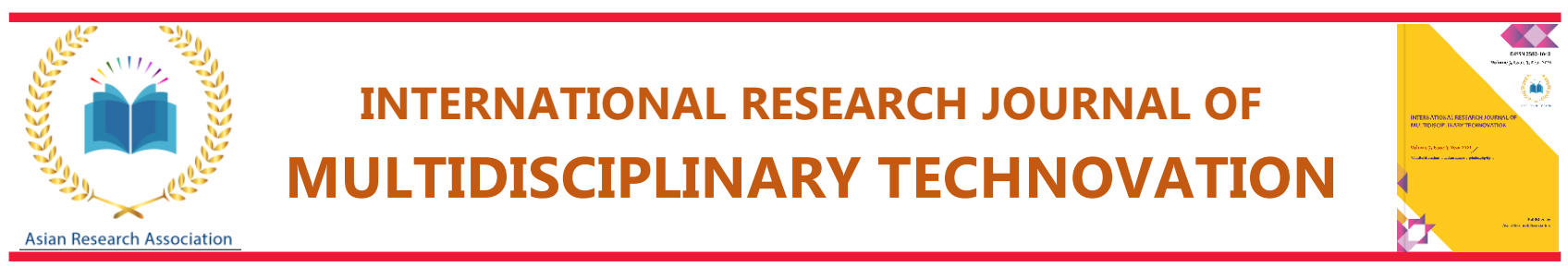

\title{
Recovery of Metal Values from Secondary Resource
}

\author{
Mahmoud A Rabah ${ }^{1,{ }^{*}}$, Omaima A El Qady ${ }^{2}$, Shaimaa A Abou El Kassem ${ }^{2}$
}

${ }^{1}$ Chemical and Electrochemical Lab., Mineral Processing Dept. Central metallurgical Research and Development Institute (CMRDI) P.O. Box 11421, Helwan, Cairo Egypt.

2 Powder Metallurgy Lab., Central metallurgical Research and Development Institute (CMRDI) P.O. Box 11421, Helwan, Cairo Egypt.

${ }^{*}$ Corresponding authors email: mrabah010@gmail.com

DOI: https://doi.org/10.54392/irjmt2222

Received: 24-12-2021; Revised: 18-02-2022; Accepted: 20-02-2022; Published: 23-02-2022

Abstract: The input waste was KanthalA4 grade alloy spired in 8-25 mm outer diameter. A sample weighing $\approx 250 \mathrm{~g}$ was leached in $\mathrm{HCl}$ or aqua regia at room temperature. The acidic leachate was filtered and the $\mathrm{pH}$ value was increased to 4.0 -9.2 with the addition of $3 \mathrm{M}$ ammonia solution. The leachate was freed from iron by $\mathrm{H}_{2} \mathrm{O}_{2}$ addition. Chromium ions were separated from nickel ions by $\mathrm{pH}$ adjustment and solvent extraction using Lewatite MP 600 ionic exchanger. Ammonium hydroxide gave insoluble hydroxide ppt that was filtered and washed. Different organic salts of acetate $\mathrm{Ni}(\mathrm{OCOCH} 3) 2$, oxalate $\mathrm{C}_{2} \mathrm{O}_{4}$, citrate $\mathrm{C}_{6} \mathrm{H}_{6} \mathrm{O}_{5}$ with $\Delta \mathrm{E}$ of $74.16 \mathrm{KJ} / \mathrm{mol}$ with $\mathrm{Ni}$ and $139.33 \mathrm{KJ} / \mathrm{mol}$ with $\mathrm{Cr}$. Inorganic salts were also prepared like $\mathrm{Ni}\left(\mathrm{NO}_{3}\right)_{2} \cdot 6 \mathrm{H}_{2} \mathrm{O}$, dichloride $\mathrm{NiCl}_{2}$, basic carbonate $\mathrm{NiCO}$. $2 \mathrm{Ni}(\mathrm{OH})_{2}$ as well as free metals of nickel and chromium. The effect of the process parameters was studied. The time of synthesis decreased by stirring at $300 \mathrm{rpm}$ by about $11 \%$. Ascorbic acid solution reduces the $\mathrm{Ni}$ and $\mathrm{Cr}$ hydroxide to their respective free metal to give spherical nanoparticles having the molecular size of 15-35 nanometer. SEM showed that Ni particles are spherical in morphology. XRD and XDS showed Ni and Cr are pure.

Keywords: Nickel and Chromium, Heating Element Scrap, Recovery of Nonferrous Metals, Solvent Extraction, Acid Leaching of Metal Scrap

\section{Introduction}

Cyanidation process may be the main technique for precious metals recovery of the mining industry. That technique consisted in an electrochemical process that oxidizes gold and reduces oxygen with cyanide solutions at $\mathrm{pH}$ values above 10.5. However, Tilley and Jefferson (2002) reported the recovery of nickel and chromium metals by thermal reduction of their salts using hydrogen gas at $300{ }^{\circ} \mathrm{C}$. Nickel hydroxide $\mathrm{Ni}(\mathrm{OH}) 2$ nickel oxide are used as catalyst intermediate and in the manufacture of Ni-Cd batteries given [1]. The chemical properties of nickel make it suitable to be combined with other elements to form many alloys [2, 3]. It imparts desirable properties as corrosion resistance, heat resistance, hardness, and strength are recommended. A process was reported [4]. in which chromium can be conveniently and inexpensively removed from chromium bearing metal scrap containing nickel and/or cobalt. It relates to scraps derived from $\mathrm{Ni}$ and Co-based superalloys containing $\mathrm{Cr}$., $\mathrm{Co}$ and/or $\mathrm{Ni}$ and possibly $\mathrm{Fe}$ as the principal constituents. [5, 6] studied a hydrometallurgy process to dissolve metal values, followed by chemical purification and/or metals recovery by some methods. Pretreatment before leaching such as calcination can be used to increase leaching rate. These methods were described complex and only successful with fine scrap material such as grindings or atomized metal. Fletcher showed that dealing with metals may provide data on tonnages treated, description of scrap arisings and the processes operated for metal extraction and refining copper, aluminum, lead, zinc, tin and other precious metals [7]. Reference is made to difficulties encountered and the efficiency of reclamation, such as the small amount of zinc recycled as metal. The future developments, wider use of oxygen in copper refining and hydrometallurgical processing of high value and complex scrap are literature. The potential for metal recovery for domestic refuse and the role of the Waste Management Advisory Council described. a technique using CYANEX 923. [8] reported that oxalic acid was employed to precipitate the Ferron, nickel, cobalt and manganese from the leaching sulfate solution of ferrochrome alloy. The authors showed that the deposition efficiency of Ferron reaches $99 \%$ and the loss rate of chromium is less than $1 \%$ when $120 \%$ theoretical quantity of oxalic acid is used under $30^{\circ} \mathrm{C}$ and terminal $\mathrm{pH}=3$. At the same time, the $\mathrm{A}$ method was given to employ precipitation, solvent extraction, and electrowinning steps [9]. A toluene solution of Cyanex 923 is used as an extractant for the separation of $\mathrm{Cr}(\mathrm{III})$ 
and $\mathrm{Ni}(\mathrm{II})$ from some commonly associated metal ions such as $\mathrm{Al}(\mathrm{III}), \mathrm{Fe}(\mathrm{III}), \mathrm{Mn}(\mathrm{II}), \mathrm{Co}(\mathrm{II}), \mathrm{Cu}(\mathrm{II}), \mathrm{Zn}(\mathrm{II})$, and $\mathrm{Pb}(\mathrm{II})$. The experiments conducted up to 10 cycles indicate a negligible loss in extraction efficiency. The electrodeposition of $\mathrm{Cr}$ (III) and $\mathrm{Ni}$ (II) offers average cathode efficiencies around 40 and $75 \%$, respectively. The recovered metals are $99.9 \%$ pure. [10] reviewed methods of separation of valuable metals from pickling solution containing nickel frum the spent liquor by solvent extraction deposition efficiencies of nickel, cobalt and manganese in the solution were 98.4, 92.2, 97.5\%, respectively. [9] recovered nickel from spent lithium and $\mathrm{N}-\mathrm{Me}$ hydride batteries by leaching with aqua regia digestion. The author reported that after leaching, >97\% of rare earth elements (REEs) were recovered with the addition of $\mathrm{NaOH}$ and $\mathrm{Na}_{2} \mathrm{SO}_{4}$ precipitants. The REEsfree solution was then further processed to separate and recover the battery metals present: $\mathrm{Mn}, \mathrm{Co}, \mathrm{Ni}$, and $\mathrm{Li}$ as a marked improvement over the previously reported. Lithium recovery levels of $60-80 \%$ extent was reported. [11] claimed recovery of chromium, nickel, and other alloying elements in stainless and heat-resisting steel. Conventional nickel electrolysis processes were particularly attractive techniques. The use of side-stream purification of process solutions was to improve the purity of nickel metal. Moreover, nickel purification by electrolysis was effective in a variety of electrolyte systems, including sulfate, chloride, and nitrate. Conventional electrorefining processes typically employed a mixed electrolyte which included sulfate, chloride, and borate. The use of an electrorefining or electrowinning system for scrap nickel recovery could be combined effectively with a variety of other processes, such as cementation, solvent extraction, ion exchange, complex-formation, and surface sorption, developed for uranium and transuranic purification.

The aim of this study is to recover metal values and some salts from the spent heating coils made of KanthalA4 grade. The suggested experimental procedure involves breaking the scrap coils to separate rings followed by leaching with mineral acids. The leachate was partially neutralized with ammonia solution to a $\mathrm{pH}$ 4. Chromium was precipitated as a- $\mathrm{Cr}(\mathrm{OH})_{3}$ at $\mathrm{pH} 4.57$ to 6.576 . Ni hydroxide precipitates at $\mathrm{pH} 9.3$. Part of. neutralized leachate reacted with $1.0 \mathrm{M}$ ascorbic acid to reduce nickel and chromium ions to their free metal particles. The remaining part of the leachate was treated with ammonia to a $\mathrm{pH}$ range 6-9.5 to precipitate insoluble hydroxide the ppt was washed with distilled water, and reacted with the acid of concern to obtain citrate, acetate, oxalate, chloride, nitrate and sulphate salts. Parameters affecting the recovery quality and extent were investigated.

\section{2- Experimental}

\subsection{Materials and Methods}

A sample of the spent heating coil scrap weighing about $2 \mathrm{Kg}$ was obtained from the scrap stores of the CMRDI institute. The sample was washed with distilled water to get rid of the dust and/or foreign ingredients and dried. It was spilled to separate rings annually on basis of its brittleness. Figure 1 shows a photograph of the coil as received and the spilled separate rings.
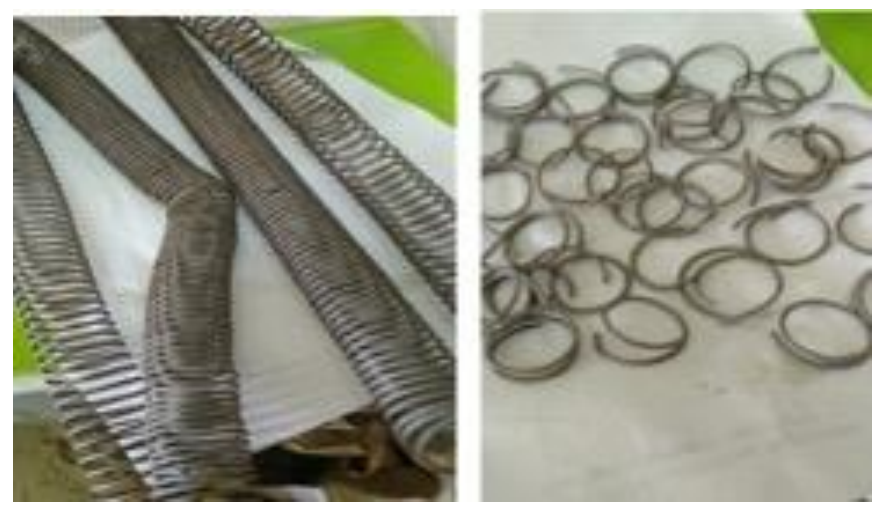

Figure 1. Photograph of the heating coil as received Spilled rings of the scrap coil

\subsection{The Chemicals Used in This Work}

The chemicals used in this work are given in Table 1.

\subsection{The process of preparation of the products}

Figure. 2 shows a sequential process of the method used in this study for the preparation of the end products.

\subsection{Determination of the physical and chemical properties}

\subsubsection{Determination of density of metal particles}

Determination of density of metal particles was carried out by liquid displacement technique with the help of a pycnometer bottle $50 \mathrm{ml}$ size.

\subsubsection{Determination of nickel and chromium}

Nickel and chromium and other metals content in the scrapped source were determined using ATI UNICAM 929 flame atomic absorption Spectrophotometer (FAAS) (Unicam Ltd., Cambridge, England). A standard blank solution containing exactly $0.1-10 \mathrm{~g} / \mathrm{L}$ metal of nickel and chromium nitrate was measured at a wavelength, 357.9 and $232.0 \mathrm{~nm}$; $\mathrm{HCL}$ current, 11.5 and $7.5 \mathrm{~mA}$; acetylene flow rate, 4.2 and $0.5 \mathrm{~L} / \mathrm{min} ; \mathrm{N}_{2} \mathrm{O}$ flow rate $4.7 \mathrm{~mL} / \mathrm{min}$ (for $\mathrm{Cr}$ ), air flow rate, $4.0 \mathrm{~mL} / \mathrm{min}$ (for Ni); slit width, 0.5 and $0.2 \mathrm{~nm}$; for $\mathrm{Cr}$ and $\mathrm{Ni}$, respectively. The straight line in the plot was taken as a reference for measuring the unknown sample. 
Table 1. Properties of the chemicals used in this study

\begin{tabular}{|c|c|c|c|}
\hline Material & properties & Purpose of use & supplier \\
\hline \multirow[t]{3}{*}{$\sup \mathrm{CH}_{3} \mathrm{COOH}$} & 90 \% SP. Gr. $1.044-1.049$ & & Riedel-de Hein \\
\hline & SP.GR.1.18 (AR) & & ADWIC \\
\hline & Min. assay $36 \%$ & Leaching & Riedel-de Hein \\
\hline Nitric acid & Fuming $69 \%$ & Process & \\
\hline $\mathrm{H}_{2} \mathrm{SO}_{4}$ & $\mathrm{H}_{2} \mathrm{SO}_{4} 95-97 \%$ & & ADWIC \\
\hline $\mathrm{HCl}$ & SP.GR.1.18 (AR) & & \\
\hline Oxalic acid & Pure crystals & Precipitation & \\
\hline Acetic acid & $60 \%$ & Synthesis of salt & Sigma, Aldrich \\
\hline Citric acid & Colorless crystals & Synthesis of salt & Sigma Aldrich \\
\hline Ascorbic acid & White solid & $\begin{array}{l}\text { Chemical reduction } \\
\text { Solvent extraction }\end{array}$ & China \\
\hline Ethyl alcohol & $96 \%$ Pure grade & Solvent extraction & ADWIC \\
\hline Acetone & Pure grade & Solvent extraction & ADWIC \\
\hline DMSO & Pure grade & Solvent extraction & ADWIC \\
\hline DMF & Pure grade & & ADWIC \\
\hline Ca carbonate, EJSF2 & Extra pure & Synthesis process & $\begin{array}{l}\text { Green Egypt } \\
\text { Siama Aldrich }\end{array}$ \\
\hline $\begin{array}{l}\mathrm{NaOH} \\
\text { hydroxide) }\end{array}$ & Pure reagent for analysis & $\begin{array}{l}\text { United Co. } \\
\text { for chemicals \&Med. }\end{array}$ & \\
\hline $\begin{array}{l}\text { Ammonium } \\
\text { hydroxide }\end{array}$ & $\begin{array}{l}25 \% \text { Pure reagent for } \\
\text { analysis }\end{array}$ & Preparations & Merck \\
\hline $\mathrm{AgNO}_{3}$ (Sliver Nitrate) & Pure reagent for analysis & $\begin{array}{l}\text { Chlorideion } \\
\text { determination }\end{array}$ & Merck \\
\hline Mono-distilled water & & Chemical reactions & \\
\hline Tap water & Ultra-Filtered & Other purposes & \\
\hline
\end{tabular}

Heating-coil scrap $\longrightarrow$ breaking yo individual rings $\longrightarrow$ Acid leaching $\longrightarrow$ filtration Filtration $\longleftarrow$ removal of $\mathrm{Fe}$ by $\mathrm{H}_{2} \mathrm{O}_{2} \longleftarrow$ Filtration $\longleftarrow \mathrm{pH}$ adjustment to 6.5 with ammonia

the acidic leachate $\longrightarrow$ Reduction of $\mathrm{Cr}$ with ascorbic acid at $\mathrm{pH} 4.6 \longrightarrow$ Filtration $\rightarrow$ Separation of

residual $\mathrm{Cr}$ by solvent $\longrightarrow$ reduction of $\mathrm{Ni}$ with ascorbic acid at $\mathrm{pH} 9.4 \longrightarrow$ Filtration

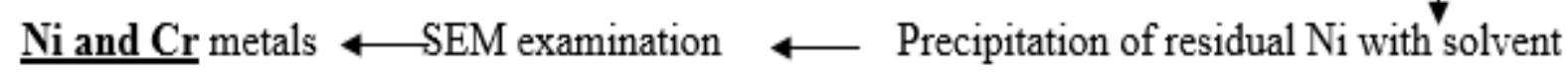
extraction

reaction of $\mathrm{Cr}(\mathrm{III})$ and $\mathrm{Ni}$ hydroxide with organic acids $\rightarrow$ crystallization and drying $\mathrm{Ni} / \mathrm{Cr}$ organic salts

Figure 2. Sequential process of the method used in this study for the preparation of the end products. 


\subsubsection{Removal of Iron from the Leachate}

Ferrous ions were removed from the acid leachate as ferric basic oxide $\mathrm{Fe}(\mathrm{OH})_{2} \mathrm{O}_{2}$ with the help of $\mathrm{H}_{2} \mathrm{O}_{2}$ addition to the acidic leachate. The filtrate contains nickel and chromium ions in nitric acid with other minor elements.

\subsubsection{Oxidation of Chromium (III) to Chromium (VI)}

Oxidation of chromium (III) to chromium (VI) using $30 \%$ hydrogen peroxide was conducted according to the method given by I. Bojanowska [12].

\subsubsection{Separation of Chromium from Nickel- Chromium Nitrate Solution}

Nickel was separated from chromium in the nitrate solution by adjusting the $\mathrm{pH}$ value using $30 \%$ ammonium hydroxide solution. Alternatively, the excellent nickel removal is performed by combining carbonate and hydroxide precipitations probably to benefit a coprecipitation phenomenon., the $\mathrm{pH}$ was adjusted by dropwise addition of $\mathrm{IN} \mathrm{NaOH}$ and an equivalent amount of $\mathrm{IN} \mathrm{CaCl} 2$ solution to simulate lime addition. Nickel selectively precipitates at $\mathrm{pH}$ of $10.3-$ 11 (McAnally, [13]. The slurry of chromium hydroxide that separates at lower $\mathrm{pH}(\approx 6)$ was filtered using vacuum suction filter fitted with a filter paper \# 42 Whatman. Remaining Chromium was separated by solvent extraction. A strongly basic anion exchange lewatit MP 600 resin was studied to separate $\mathrm{Cr}$ from the filtrate. An azo resorcinol 4-(2-pyridylazo) dyestuff was used as a complexing agent. Adsorption isotherms were modelled in an ethanol/acetic acid/water media. The loaded resin is regenerated using $4 \mathrm{M} \mathrm{HCl}$ whereby the eluted metal species are recovered. Mere anion exchangers could not uptake metal ions unless they reacted with the dye to form negatively charged complexes. Trivalent chromium showed significant uptake at $\mathrm{pH}$ range of 3.5-4.5. Cadmium, zinc and nickel ions formed complex compounds in the alkaline medium. The electrostatic interaction and formation of complex compounds identified the major adsorption mechanisms.

\subsubsection{Determination of the equilibrium constant $K_{d}$ of the solvent extraction process}

The equilibrium constant $\mathbf{K}_{\mathbf{d}}$ value of the separation of residual chromium remaining after $\mathrm{pH}$ separation step from $\mathrm{Ni}-\mathrm{Cr}$ iron-free solution was calculated from the relation of the weight of $\mathrm{Cr}$ in the organic and liquid phases [14].

\subsubsection{SEM and XRD examinations}

Malvern Panalytical's X-ray diffractometer was used to determine the article shape, size, Crystal structure and Phase quantification of the prepared nickel and chromium metals. SEM images were performed using Philips XL30 Scanner electron microscope.

\section{3- Results}

Table 2 shows the metals content in the scrap sample.

Table 2. The metals content in the scrap sample

\begin{tabular}{|l|c|c|}
\hline \multicolumn{1}{|c|}{ The acid leachate } & \multicolumn{2}{|c|}{ Fe-free solution } \\
\hline \multicolumn{1}{|c|}{ Metal } & Wt. \% & Wt. \% \\
\hline Nickel & 58.8 & 77.95 \\
Chromium & 16.62 & 22.01 \\
Iron & 24.58 & 0.02 \\
Other minor & & 0.01 \\
\hline
\end{tabular}

Figure 3 shows the extent of leaching the spent heating coil materials $(\mathrm{HC})$ using different concentrations of $\mathrm{HCl}$ acid and aqua regia as a function of time at room temperature It can bwa seen that the leaching extent increases regularly with time whereby the maximum extent of leaching amounts to $44 \%$.

Figure 3 shows the extent of leaching the spent materials using aqua regia as a function of time at room temperature It can be seen that the leaching extent increases regularly with time whereby complete leaching takes place at $\geq 60$ minutes. Finding given in Fig. 4 shows that the internal temperature of the leaching process increased due to the exothermic nature of the reaction. Figure 5 shows the effect liquid: solid mass ratioof on the extent of acid leaching of the scrap at room temperature. It is seen that liquid: solid mass ratio becomes significant with $\geq 1.15: 1$ mass ratio. Figure. 6 shows the effect of reaction temperature in ${ }^{\circ} \mathrm{C}$ on the extent of formation of the different organic salts of $\mathrm{Ni}$ and $\mathrm{Cr}$. $\mathrm{Ni}$ acetate and citrate are readily obtained as compared to the formation of the same salts with chromium.

Figure. 7 shows the Arrhenius plot of $1 / \mathrm{T}^{\circ} \mathrm{K} \times 10$ 4 against In weight of formation of the different salts of $\mathrm{Ni}$ and $\mathrm{Cr}$. The calculated $\Delta \mathrm{E}$ value with nickel amounts to $74.16 \mathrm{KJ} / \mathrm{mol}$ and $139.33 \mathrm{KJ} / \mathrm{mol}$ with chromium. Fig 8 shows SEM of $\mathrm{Ni}$ and $\mathrm{Cr}$ particles as obtained by reducing $\mathrm{Ni}$ nitrate with $1 \mathrm{M}$ ascorbic acid. The particle size of nickel amounts to $15-25 \mathrm{~nm}$ and about $35 \mathrm{~nm}$ with chromium. The global recovery extent amounts to98.6\% with nickel and $96.4 \%$ with chromium

SEM investigation proved that nickel particles as explored by JCPDS file no $04-850$ are spherical in shape with smaller size typically $10-40$ nanometers as compared to chromium particles that are octahedral in shape. 

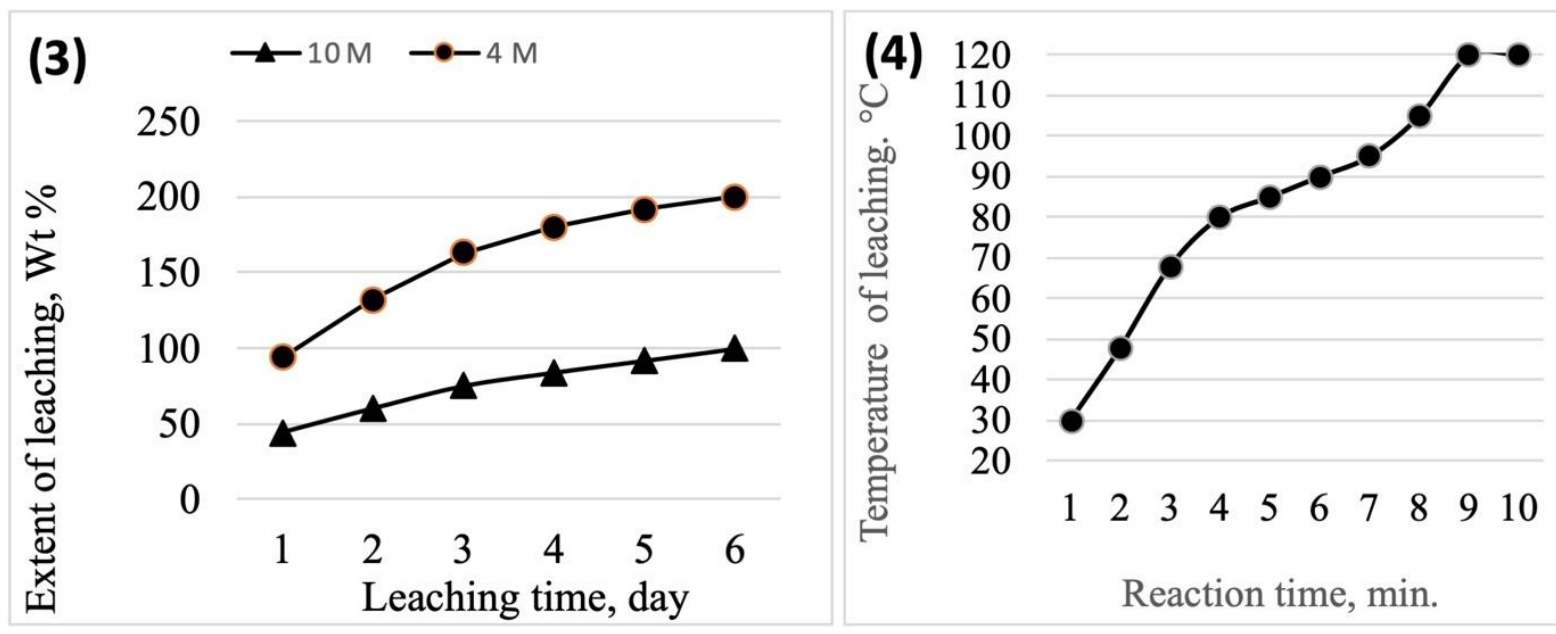

\section{(5)}

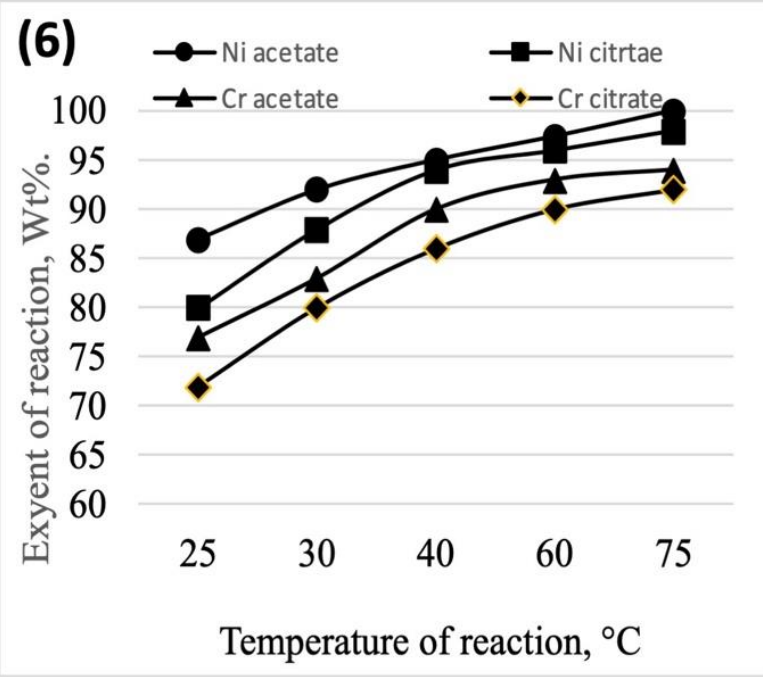

Figure 3-6. 3. Leaching extent of spent $\mathrm{HC}$ with $10 \mathrm{M}$ and $4 \mathrm{M} \mathrm{HCl}$ at room temperature 4. Temperature change of the leaching process during the reaction with aqua regia 5. the extent of leaching the scrap material with different liquid: solid mass ratio using $10 \mathrm{M} \mathrm{HCl}$ at room temperature 6 . Effect of temperature on the extent of formation of the different salts of $\mathrm{Ni}$ and $\mathrm{Cr}$.

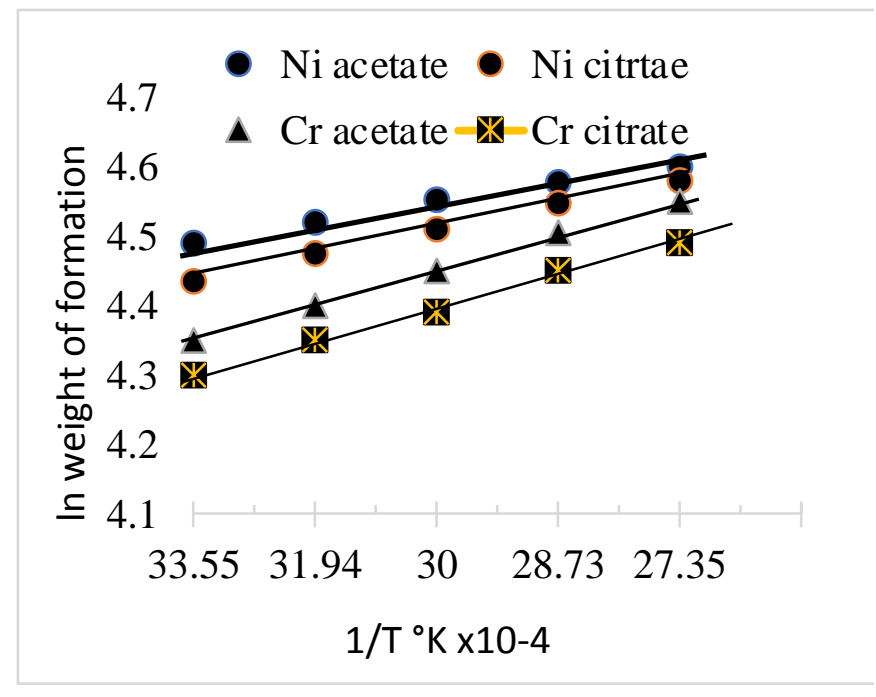

Figure 7. The Arrhenius plot of the formation of nickel and chromium salts 

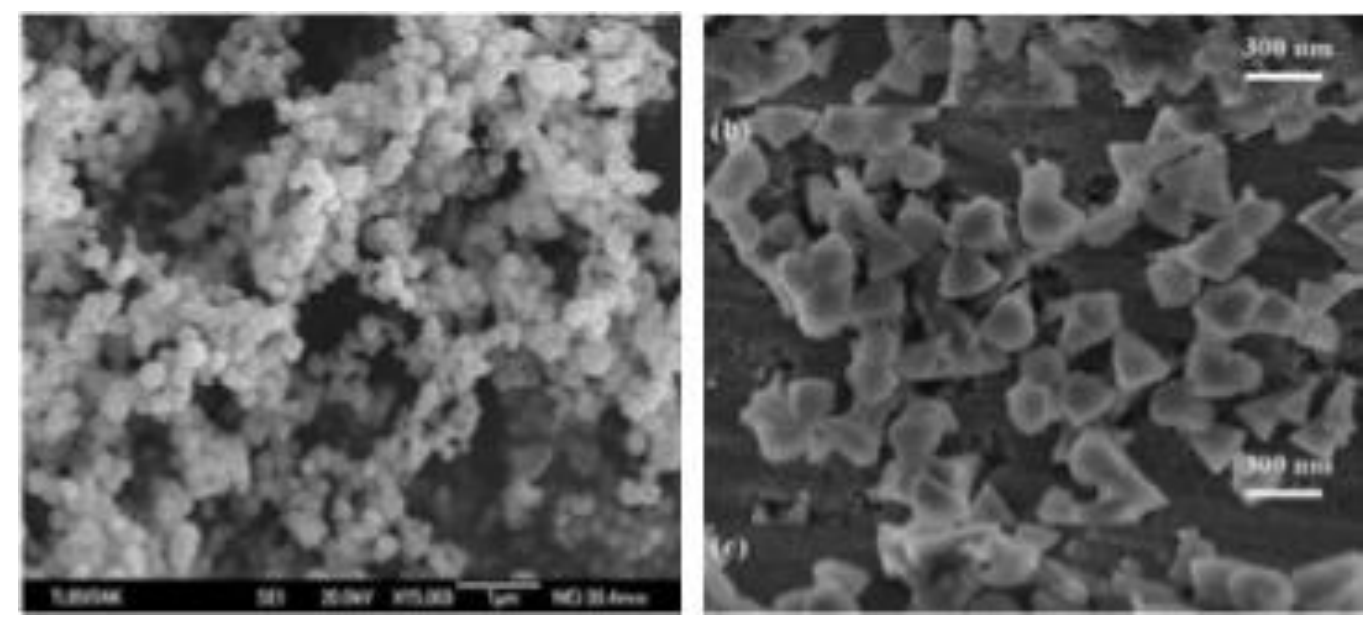

Figure 8. The SEM images of Bi (JCPDS file no 04 -850) and Cr particles

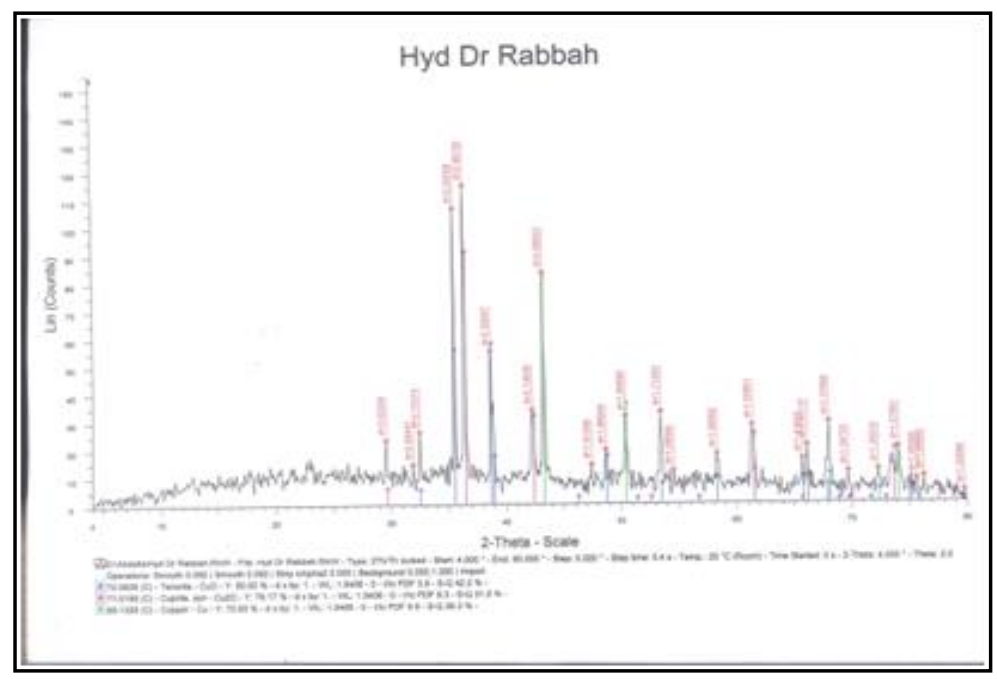

Figure 9. The XRD pattern of the recovered $\mathrm{Ni}$

In the XRD pattern of the recovered $\mathrm{Ni}$ and $\mathrm{Cr}$ particles (Fig.9), the main peaks appeared at $2 \theta 48,54$ and 75 with $\mathrm{Ni}$. The corresponding peaks with chromium appeared at $2 \theta$ of $28,33,35,58$ and 74 , the XRD pattern indicated that that $\mathrm{Ni}$ is crystalline. The global recovery efficiency of nickel (metal + salts) amounts to $98.6 \mathrm{Wt}$. \% and amounts to $96.4 \mathrm{Wt}$. \%. with chromium.

\section{Discussion}

Nickel-chrome $\mathrm{Ni}-\mathrm{Cr}$ may be alloyed with iron together with some minor elements used as resistance wire, space heaters, electric furnaces and other similar applications. The alloy shows that chromium is soluble in nickel at a maximum weight pct of $47 \%$ at its eutectic temperature and decreases to about $30 \%$ at room temperature. Such nickel-chrome alloys have excellent electrical resistance with simultaneous generation of temperature. The alloy has good oxidation, corrosion and wear resistance. The scrap used in this study contains 16.62 wt. pct of chromium as revealed in Table 1.
With repeated heating and cooling-cycles the $\mathrm{Ni}-\mathrm{Cr}$ spiral is subjected to structural changes and rend brittle. Fig. 2 shows a photograph of the spent $\mathrm{Ni}-\mathrm{Cr}$ coil as received and after splitting to single rings to make leaching with mineral acids easier $\mathrm{Ni}$ and $\mathrm{Cr}$ metals are present in the leachate together with iron. The process of recovering $\mathrm{Ni}$ and $\mathrm{Cr}$ starts by getting rid of iron by conversion to insoluble ferric hydroxide by $\mathrm{H}_{2} \mathrm{O}_{2}$

$$
2 \mathrm{Fe}^{+2}+\mathrm{H}_{2} \mathrm{O}_{2}+4 \mathrm{OH}^{-} \rightarrow 2 \mathrm{Fe}(\mathrm{OH})_{3}
$$

The ppt of ferric hydroxide is filtered and the leachate contains $\mathrm{Ni}$ and $\mathrm{Cr}$ chloride or nitrate

recovered in nanoparticle size amounting to 15 $25 \mathrm{~nm}$ and about $35 \mathrm{~nm}$ with chromium. Figure 2 represents a sequential process route to achieve the target from the waste material. The leaching step was performed using $\mathrm{HCl}$ with different concentrations and with aqua regia. The process of leaching is friendly environment safe with low cost.

$$
\mathrm{Ni}+2 \mathrm{HCl} \longrightarrow \mathrm{NiCl}_{2}+\mathrm{H} 2
$$




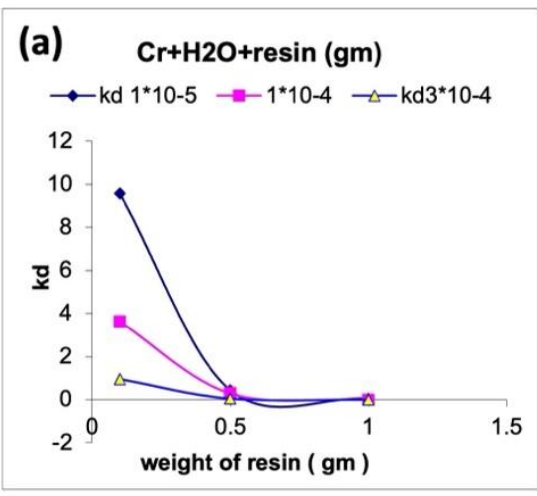

(d) $\mathrm{Cr}+80 \%$ et + dye $+0.1 \mathrm{gm}$ resin

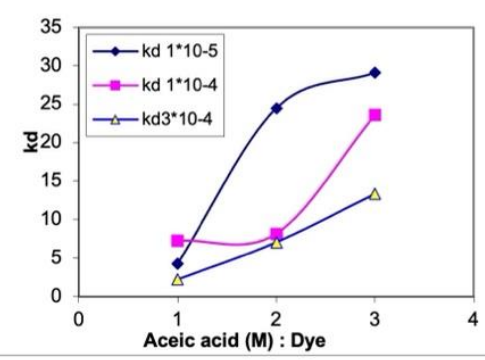
(b) $\mathrm{Cr}+\mathrm{H2O}+\underset{\text { resin }}{\text { acetic acid }}(0.1-1 \mathrm{M})+0.1 \mathrm{gm}$

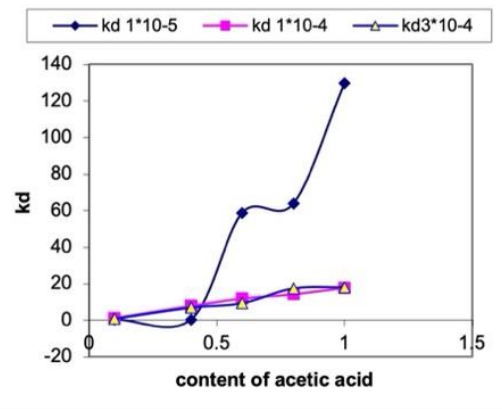

(e) $\mathrm{Cr}+80 \%$ et+acetic acid $(0.1-1 \mathrm{M})+$ dye

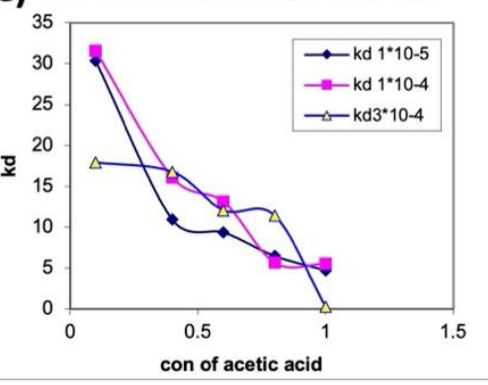
(C) $\mathrm{Cr}+80 \%$ et +acetic acid $(0.1-1 \mathrm{M})+0.1 \mathrm{gm}$
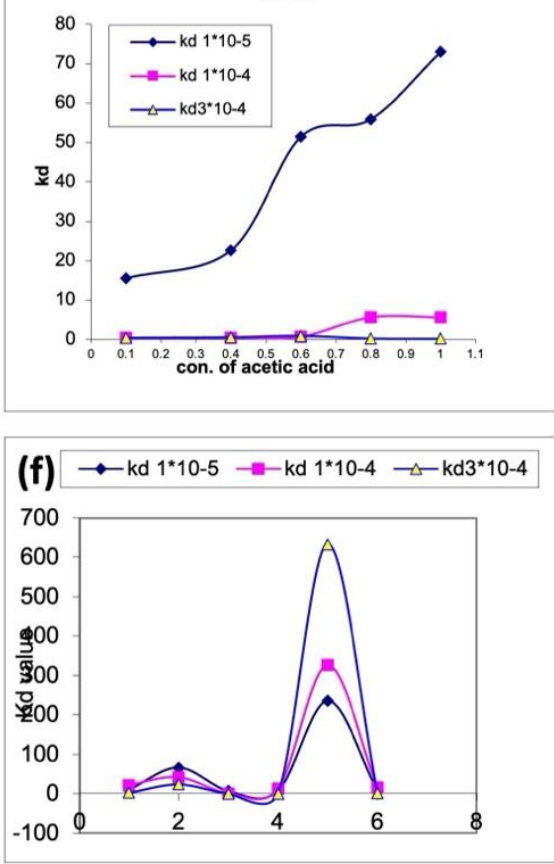

Figure10a. Effect of resin weight on the $\mathrm{Kd}$ value of $\mathrm{Kd} \mathrm{Cr}$ uploading $\mathrm{Cr}$ in $\mathrm{Cr}$ Acetic $+\mathrm{H}_{2} \mathrm{O}+$ resin system b. Effect of acetic acid addition on the value of uploading $\mathrm{Cr}$ from $\mathrm{Cr}+\mathrm{H} 2 \mathrm{O}+$ acid + resin system 10c. Effect of resin weight on the $\mathrm{Kd}$ value of $\mathrm{Cr}$ uptake from $\mathrm{Cr}+80 \%$ et +acetic acid $10 \mathrm{~d}$. Effect of acetic acid addition on the $\mathrm{K}_{\mathrm{d}}$ value of $\mathrm{Cr}+80 \%$ et $+.1 \mathrm{gm} \mathrm{resin} / 20 \mathrm{ml}+$ dye $0.1-1 \mathrm{M})+0.1 \mathrm{gm}$ resin $10 \mathrm{e}$. Effect of acetic acid concentration on $\mathrm{Cr}$ Uptake $\mathrm{Cr}+80 \%$ et + acetic acid $(.1-1 \mathrm{M})+$ from $\mathrm{cr}+.1 \mathrm{gm}$ resin+80\%et $80 \%+$. $10 \mathrm{f}$. Effect of different solvents (ethanol, DMSO, DMF on $\mathrm{K}_{d}$ value of $\mathrm{Cr}$ uptake $1 \mathrm{gm}$ resin/20ml dye resin/20ml+dye

It is usually come upon as the green hexahydrate, the formula of which is frequently written $\mathrm{NiCl} 2 \cdot 6 \mathrm{H} 2 \mathrm{O}$

$$
\mathrm{NiCl}_{2}+6 \mathrm{H}_{2} \mathrm{O} \longrightarrow \mathrm{NiCl}_{2} \cdot 6 \mathrm{H}_{2} \mathrm{O}
$$

and the metal hexahydrate forms metal aquo complex $[\mathrm{Ni}(\mathrm{H} 2 \mathrm{O}) 6]^{2+} \quad$ Dehydration of the $\mathrm{NiCl} 2 \cdot 6 \mathrm{H} 2 \mathrm{O}$ or $\mathrm{NiCl}_{22} \cdot 6 \mathrm{H}_{2} \mathrm{O}$ gives the yellow anhydrous $\mathrm{NiCl}_{2}$. Dehydration successively causes passivation of the nickel metal surface. The latter phenomenon explains why $10 \mathrm{M} \mathrm{HCL}$ is less reactive as compared to less concentrated $4 \mathrm{M}$ acid as confirmed by the results given in Figure 3b.

The same reaction of $\mathrm{HCl}$ takes place with chromium as with nickel provided that $\mathrm{Cr}(\mathrm{II}) \mathrm{Cl}_{2}$ is formed.

$$
\begin{aligned}
& \mathrm{Cr}_{(\mathrm{s})}+2 \mathrm{HCl}_{(\mathrm{aq})} \rightarrow \mathrm{Cr}^{2+}{ }_{(\mathrm{aq})}+2 \mathrm{Cl}_{(\mathrm{aq})}+\mathrm{H}_{2(\mathrm{~g})} \text { or } 2 \mathrm{Cr} \\
& +6 \mathrm{H}^{+} 2 \mathrm{Cr}^{3+}+3 \mathrm{H}_{2}
\end{aligned}
$$

Chromium metal dissolves in dilute $\mathrm{HCl}$ acid to form $\mathrm{Cr}$ )II) ion together with hydrogen gas provided that some metal samples may be resistant to the acid attack.

Leaching the scrapped source was also tested using aqua regia. Results depicted in Figure 4 shows complete acid leaching is scored after 1 hour. The main disadvantage of using this strong corrosive solution is that leaching proceeds vigorously with the evolution of hazardous nitrogen dioxide. The reaction involved the following sequence.

$$
\begin{aligned}
& \mathrm{HCl}+\mathrm{HNO}_{3} \longrightarrow \mathrm{Cl}^{-}+\mathrm{NO}+2 \mathrm{H}^{+}+2 \mathrm{O} \\
& \mathrm{M}(\mathrm{N} / \mathrm{Cr})+2 \mathrm{O} \longrightarrow \mathrm{MO}_{4} \\
& \mathrm{NO}+\mathrm{O} \longrightarrow \mathrm{NO}_{2} \\
& \mathrm{MO}+\mathrm{NO}_{2} \longrightarrow \mathrm{MNO}_{3}
\end{aligned}
$$

Where $\mathrm{M}$ is for $\mathrm{Cr}$. It is worthy to note that the acid leachate produces metal hydroxide ppt after reaction with ammonia. Careful analysis revealed that some of the chromium is still remaining in a low concentration of about $0.0 \mathrm{x}$ mol. Basic carbonate of nickel and chromium can be synthesized from their nitrate salt by reacting with ammonium carbonate.

$\mathrm{M}\left(\mathrm{NO}_{3}\right)_{2}+\left(\mathrm{NH}_{4}\right)_{2} \mathrm{CO}_{3}+\mathrm{H}_{2} \mathrm{O} \rightarrow \mathrm{MCO}_{3} .2 \mathrm{H}_{2} \mathrm{O}+2 \mathrm{NH}_{4} \mathrm{NO}_{3}$. (10)

The study includes determination of the $\mathrm{K}_{d}$ value of chromium uptake as affected by addition of resin, acetic acid, ethanol + acetic acid, ethanol + dye, acetic acid from $\mathrm{Cr}+$. +1gm resin+80\%ethanol $80 \%+$ dye without resin (Figure. 10 a-f) and using different solvents ; ethanol, dimethyl-sulphoxide DMSO, acetone and dimethyl furane. Results revealed that mere anion exchanger could not uptake $\mathrm{Cr}$ metal ions unless they reacted with the dye to form negatively charged complexes. The residual metal was separated by solvent extraction using LEWATIT MP 600 ion exchange resin. Results are graphically represented in Figure 10a through Figure $10 f$. 


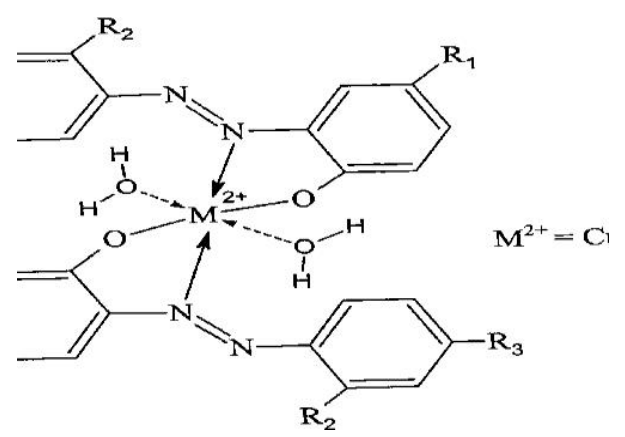

Figure 11. The structure of the Azo-metal complex
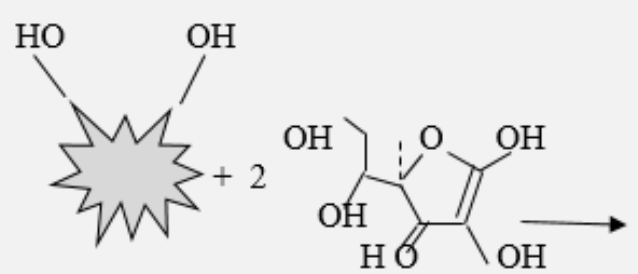

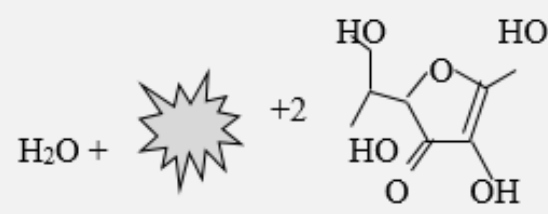

Nickel hydroxide +2 ascorbic acid water Nickel metal oxidized ascorbic acid

Figure 12. shows the global recovery efficiency of $\mathrm{Ni}$ and $\mathrm{Cr}$ recivery extent

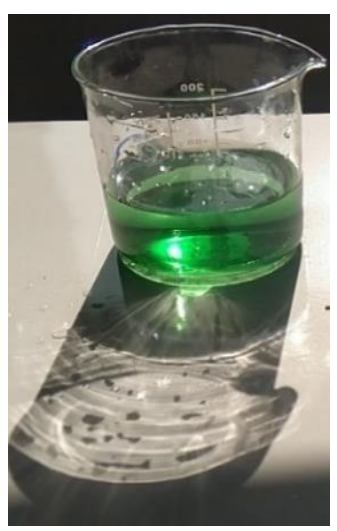

$\mathrm{Ni} / \mathrm{Cr}$ leachate nitrate solution

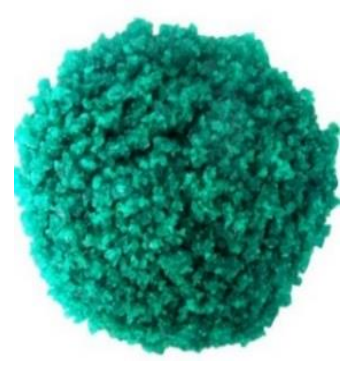

Ni nitrate solid

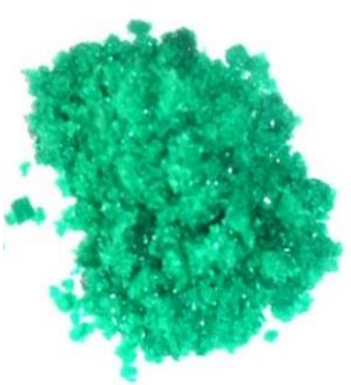

Nickel acetate

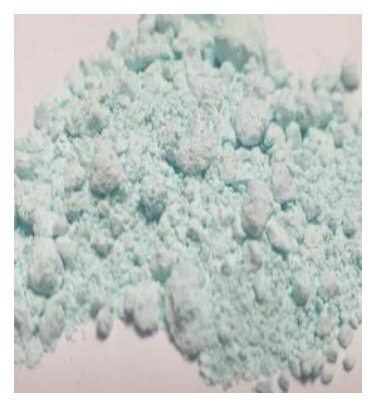

Ni oxalate

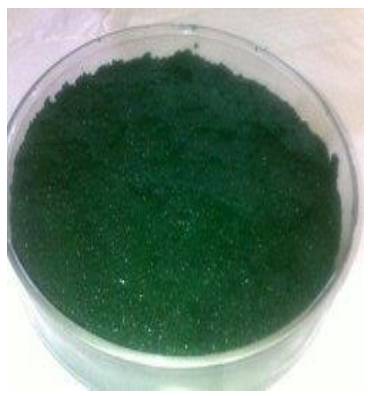

Chromium chloride

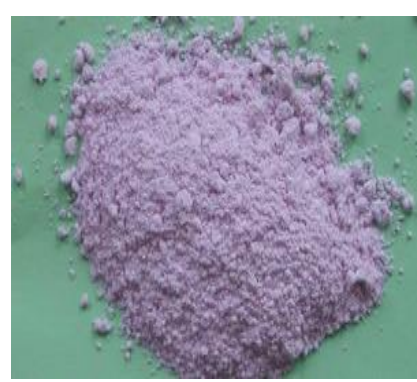

Chromium chloride hexahydrate

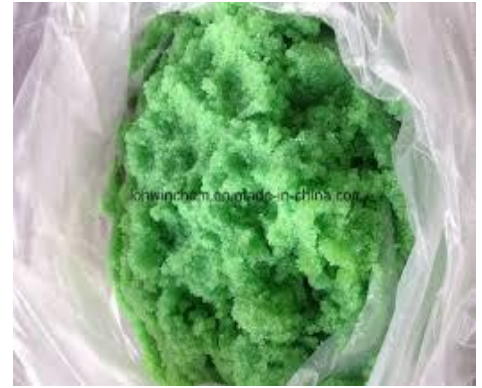

chromium chloride anhydrous

Figure 13. shows the global recovery efficiency of $\mathrm{Ni}$ and $\mathrm{Cr}$ recivery extent 
Nickel metal present in the heating coil structure alloyed with chromium metal as confirmed with SEM image given in Figure 8.

Preparation of chromium oxalate in solution can form complex, metals such as nickel can be precipitated at the same time. The reactions involved are as follows:

$$
\mathrm{Me}^{2+}+\left[\mathrm{C}_{2}\right] \mathrm{O}_{4}{ }^{2-}=\mathrm{MeC}_{2} \mathrm{O}_{4}
$$

$\mathrm{Me}$ is $\mathrm{Fe}, \mathrm{Ni}, \mathrm{Cr}$ in the solution. When the reaction reaches the balance:

$$
\begin{gathered}
\left.\mathrm{K}_{\mathrm{sp}}=\left[\mathrm{Me}^{2+}\right]\left[\mathrm{C}_{2}\right] \mathrm{O}_{4}{ }^{2-}\right] \\
{\left[C_{2}\right] O_{4^{2}}=\frac{K^{0} S P}{c\left(M e^{2+}\right) / C_{0}}}
\end{gathered}
$$

$\mathrm{Cr}$ ) in the solution

$\mathrm{C}\left(\mathrm{Me}^{2+}\right)$ is the concentration of metal $(\mathrm{Fe}, \mathrm{Ni}$, $\mathrm{C}_{2} \mathrm{O}_{4}{ }^{2}$ in the solution is determined by the following reaction:

$$
\left.\mathrm{H}_{2} \mathrm{C}_{2} \mathrm{O}_{4}\right]=2 \mathrm{H}^{+}+\left[\mathrm{C}_{2} \mathrm{O}_{4}{ }^{2-}\right)
$$
$=4.0 \times 10^{-6}$

The ionization constant: $\mathrm{K}^{0} \mathrm{sp}_{1}=3.5 \times 10^{-2}, \mathrm{~K}_{\mathrm{a} 2}$ So:

$$
C\left(H^{+}\right)=\frac{\left\{K_{a l^{\theta}} K_{a 2}{ }^{\theta} C\left(H_{2} C_{2} O_{4}\right) / C^{0}\right\}^{1 / 2}}{C\left(C_{2} O_{4^{2-}}\right) / C^{0}}
$$

precipitation initial $\mathrm{pH}$ value is calculated as:

$$
\mathrm{pH}=-\log (\mathrm{C} \mathrm{H}+)
$$

Therefore,

$$
\left.p^{H=}-\log \right) \frac{\left\{K_{a l^{\theta} K_{a 2} C} C\left(H_{2} C_{2} O_{4}\right) / C^{0}\right\}^{1 / 2}}{C\left(C_{2} O_{4} 4^{-}\right) / C^{0}}
$$

When $\left[\mathrm{C}_{22} \mathrm{O}_{4}{ }^{2}\right]$ in equation (13) substitutes to equations (14) and (15), the precipitation counterparts at the initial $\mathrm{pH}$ value can be calculated by equation (17). According to the initial concentration of the materials in the solution, and applying equation (15), we can calculate the critical $\mathrm{pH}$ value for the metal ions of concern. Accordingly, the precipitation $\mathrm{pH}$ value for iron in the solution with hydrogen peroxide would be manifested at low $\mathrm{pH}$ whereas the other metals such as chromium precipitates at higher $\mathrm{pH}$ value of 4.6-6.2 and 10.3 - 11 with nickel. Citric acid proved more aggressive than acetic acid due to higher metal complexation and because the ionization constant of acetic acid is incomplete [15]. The prepared organic salts of nickel and chromium exhibit complex formation of these compounds.

Figure 13 shows photographs of $\mathrm{Ni}$ nitrate, citrate and oxalate and chromium chloride solid salts

The different colors of nickel and chromium salts as shown in Figure 13. may be ascribed to the displacement of electrons of the metal ionic configuration from the $\mathrm{d}$ orbital to a higher or lower level. Certain wavelengths are absorbed in the process of complex formation so that subtractive color takes place and the coordination complex solution becomes colored [16-18].

\section{Conclusion}

The outmost findings of this study conclude that spent $\mathrm{Ni}-\mathrm{Cr}$ heating alloy contains appreciable amounts of nickel and chromium that cannot be discarded without making effort to recover its content of metal values. The suggested process revealed a successful way to achieve the target with no need for sophisticated tools, chemicals or experimental techniques. The method is a friendly environment and simple. It involves breaking of the useless coil to single rings, leaching with mineral acids. Part of the leachate reacts with ascorbic acid in slightly acidic medium to give nickel and chromium nanoparticles. The average particle size of nickel amounts to $15-25 \mathrm{~nm}$ and about $35 \mathrm{~nm}$ with chromium. The other part of the leachate reacted with ammonia to form hydroxide ppt of nickel and chromium at different $\mathrm{pH}$ values. The hydroxide compound reacts with some organic and inorganic acids to form the respective salts. The global recovery extent amounts to $98.6 \%$ with nickel and $96.4 \%$ with chromium.

\section{References}

[1] D.H. Antonsen, D.T. Meshri, (2005) Nickel compounds, Kirk-Othmer Encyclopedia of Chemical Technology, John Wiley \& Sons, New York. [DOI]

[2] NTP, (2000) Final Report on Carcinogens Background Document for Metallic Nickel and Certain Nickel Alloys, Research Triangle Park, North Carolina.

[3] J.H. Tundermann, J. K. Tien, T.E. Howson, (2005) Nickel and nickel alloys Kirk-Othmer Encyclopedia of Chemical Technology, John Wiley \& Sons, New York. [DOI]

[4] G. J. O'Connell, G.D. Tisdale, (1995) Patent for Pretreatment of chromium-bearing metal scrap to remove chromium, Justia Patents.

[5] H. Kenworthy, V.A. Nieberlein, A.G. Starliper. (1959) Experimental Extraction of Strategic Components From S-816 Alloy Scrap, Department of the Interior, Bureau of Mines, United States.

[6] H. Kenworthy, V.A. Nieberlein, A.G. Starliper, (1993) Experimental Extraction of Strategic Components from S816 Alloy Scrap, Department of the Interior, Bureau of Mines, United States.

[7] A.W. Fletcher, (1976) Metal Recycling from Scrap and Waste Materials, Proceedings of the Royal Society of London. Series A, 
Mathematical and Physical Sciences, 351 (1976) 151-178. [DOI]

[8] F. Liu, C. Peng, A. Porvali, Z. Wang, B.P. Wils, $M$. Lundström, Synergistic Recovery of Valuable Metals from Spent Nickel-Metal Hydride Batteries and Lithium-Ion Batteries, ACS sustainable chemistry engineering, 7 (2019) 16103-16111. [DOI]

[9] J. Liu, G. Hu, K. Du, Zh. Peng, W. Wang, Y. Cao, (2014) The New Technique on Separation of $\mathrm{Cr}$ and $\mathrm{Fe}$ as Well as $\mathrm{Ni}-\mathrm{Co}-\mathrm{Mn}$ Impurity in Leaching Sulfate Solution of Ferrochrome Alloy, Journal of Nonferrous Metals, 55 (2014) 533537. [DOl]

[10] A. Devi, A. Singhal, R. Gupta, P. Panzade, (2014) A study on treatment methods of spent pickling liquor generated by pickling process of steel, Clean Technologies and Environmental Policy, 16 (2014) 1515-1527. [DOI]

[11] F. P. John, (1991) Chromium, Nickel, and Other Alloying Elements in U.S.-produced Stainless and heat resisting steel, Bureau of Mines, USA.

[12] I. Bojanowska, Recovery of Chromium from Sludge Formed after Neutralization of Chromic Wastewater, Polish Journal of Environmental Studies, 2 (2002) 117-121.

[13] S.L. McAnally, L. Benefield, R.B. Reed, (1984) Nickel Removal from a Synthetic NickelPlating Wastewater Using Sulfide and Carbonate for Precipitation and Coprecipitation, Separation Science and Technology, 19 (1984) 191-217. [DOI]

[14] N. Badawy, M.A. Rabah, R. Hasan, Separation of some heavy metal species from electroplating rinsing solutions by ion exchange resin, International Journal of Environment and Waste Management, 12 (2013) 33-51. [DOI]

[15] B. Gupta, A. Deep, Siv N. Tandon, Recovery of Chromium and Nickel from Industrial \& Engineering Chemistry Research, 41 (2002) 2948-2952. [DOI]

[16] C.L. Kusik, (1981) Pyrometallurgical Recovery of Chromium from Scrap Metals, U.S. Department of the Interior, Bureau of Mines.

[17] R.D. Tilley, D. A. Jefferson, The preparation of chromium, nickel and chromium-nickel alloy nanoparticles on supports, Journal of Materials Chemistry, 12 (2002) 3809-3813.[DOI]

[18] A.L. Tsienman, L.M. Pischik, CorrosionElectrochemical behavior of metals in organic media, Elektroklimiya, 15 (1979) 87-90.
Conflict of interest

The Authors have no conflicts of interest to declare that they are relevant to the content of this article.

Does this article screened for similarity? Yes

\section{About the License}

(C) The Author(s) 2022. The text of this article is open access and licensed under a Creative Commons Attribution 4.0 International License. 